\title{
Predicting the launch feel of automatic and dual clutch transmissions
}

\author{
Neil Roberts \\ Mike Dempsey \\ Claytex Services Ltd. \\ Edmund House, Rugby Road, Leamington Spa, CV32 6EL \\ neil.roberts@ claytex.com \\ mike.dempsey@claytex.com
}

\begin{abstract}
The Powertrain Dynamics Library (PTDynamics) has been developed using a new approach to modelling the mechanics of rotating MultiBody systems. This paper will highlight the recent developments within the PTDynamics library with a focus on the dynamic torque converter and wet clutch models that enable the prediction of the launch feel of automatic and dual clutch transmission equipped vehicles. Two examples are presented: one that compares the effect of oil temperature on the initial launch of a vehicle with a dual wet-clutch transmission; and a second that compares the behaviour of steady state and dynamic torque converter models.
\end{abstract}

Keywords: powertrain dynamics, driveability, dynamic torque converter, wet clutch, automatic transmission, dual-clutch transmission

\section{Introduction}

The transmission and driveline of a vehicle have a large influence on the customer driving experience and perception of quality, as well as the efficiency and performance of the vehicle. The influence of hybridization within a vehicle has greatly increased the architecture variants available to vehicle manufacturers and consequently has complicated the selection of the most efficient hardware solution.

The Powertrain Dynamics (PTDynamics) library has been developed as a commercial Modelica library to aid evaluation of the many technology and topology options. It also provides the capability to model powertrain systems in sufficient detail to support the design and validation of the associated control systems and to optimize the vehicle's response to driver inputs.

The initial application of the library has been the transmissions and drivelines within automotive applications but it can be applied to any powertrain system. This paper explores some of the recent additions to the library that are used in the simulation of vehicle transients such as initial launch, tip-in and tip-out and gear shifting. Two examples are presented illustrating how the new additions enhance the level of detail that can be included in models to predict the initial launch of vehicles with automatic and dual clutch transmissions.

\section{Powertrain Dynamics Library}

\subsection{Overview}

Transmission and driveline systems comprise a number of key components that influence their dynamic behaviour and efficiency. The PTDynamics library has been developed to provide models for all of these components and assemblies as easy to use MultiBody models. The design objective is to make it easy to assemble a MultiBody powertrain model and achieve good simulation performance and results without having to develop a detailed knowledge of Modelica.

The range of components included in the first version of the PTDynamics library and the fundamental approach used to model the mechanics are described in [1]. This range of components is continually enhanced and refined with this paper describing some of the more significant recent developments.

\subsection{Dynamic torque converter}

In automatic transmissions the engine and gearbox are coupled by a torque converter. This is typically modelled using the steady state performance curves for the torque converter that relate speed ratio, torque ratio and capacity factor (k-factor, MPC2000, or cfactor), see Figure 1 for an example of these curves. These curves are readily available from the torque converter manufacturers and make it relatively easy to implement a steady state torque converter model. Most simulation tools only offer this type of steady state torque converter model that works well for drive cycle studies but is inadequate for the simula- 


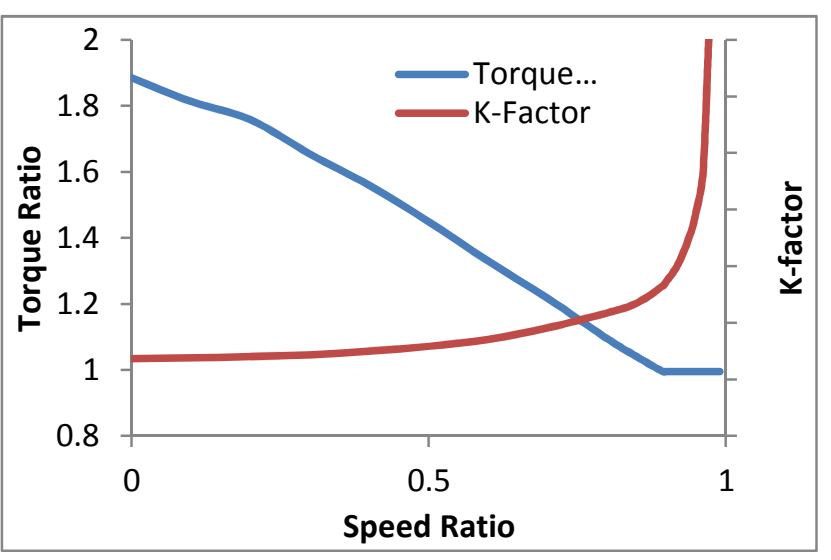

Figure 1: Steady state torque converter performance curves (speed ratio, torque ratio and $\mathrm{k}$-factor)

tion of transient events such as launch, tip-in, tip-out or gear shifting.

The problem is that models based on these curves cannot capture the transient behaviour of the torque converter which has a significant impact on the driving experience. During large transient events such as initial launch, gear shifting and driver tip-in and tipout events the transient response of the torque converter has an impact on the vehicle response and the perception of performance experienced by the driver.

A dynamic torque converter model has been implemented to overcome this problem and enable the torque converters fluid inertia and stator dynamic behaviour to be included in simulations. The model is based on the nonlinear lumped parameter model derived in Hrovat and Tobler [3] that describes the converter dynamics. It has been implemented to fit within the PTDynamics framework for a torque converter model which means that the user can very easily switch between an existing steady state torque converter model and the new dynamic torque converter model.

The basic layout of a 3 element torque converter is shown in Figure 2 with the key parts identified. The impeller is connected to the engine, the turbine is connected to the gearbox and the stator is connect-

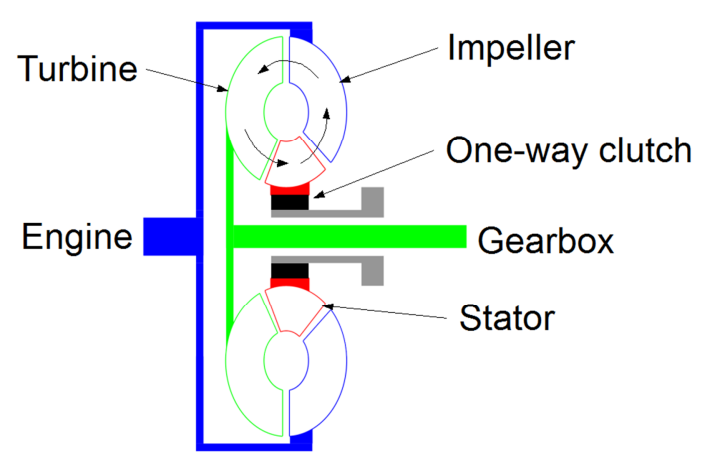

Figure 2: Schematic of a 3 element torque converter showing the fluid flow direction in the driven condition ed to the gearbox housing via a one-way clutch. Energy is transferred between these 3 components by the hydraulic fluid within these control volumes (impeller, stator, turbine).

The moment-of-momentum equation is applied to each of these control volumes and relates the rotational velocity of the mechanical components and the torque to a fluid flow velocity along the torque converter rotational axis. This results in a single first order state equation for each element and for the impeller this gives the following equation:

$$
\begin{aligned}
& I_{i} \dot{\omega}_{i}+\rho S_{t} \dot{Q}=-\left(\omega_{i} R_{i}^{2}+R_{i} \frac{Q}{A} \tan \alpha_{i}-\omega_{s} R_{s}^{2}-\right. \\
& \left.R_{s} \frac{Q}{A} \tan \alpha_{s}\right) Q+\tau_{i}
\end{aligned}
$$

This equation relates the speed of the impeller $\left(\omega_{\mathrm{i}}\right)$, torque on the impeller $\left(\tau_{\mathrm{i}}\right)$, its radii at the centre of its outlet port $\left(\mathrm{R}_{\mathrm{i}}\right)$, the angle of the blade surface to the normal $\left(\alpha_{\mathrm{i}}\right)$ and the fluid volume flow rate $(\mathrm{Q})$ is related to the conditions at its input from the stator. The state equations for the turbine and stator are of a similar form.

The fluid state equation links the relationship between the fluid volume flow rate $(\mathrm{Q})$ and the mechanical inertia velocities $\left(\omega_{i, t, s}\right)$ using a conservation of momentum energy balance given by:

$$
\begin{aligned}
& \rho\left(S_{i} \dot{\omega}_{i}+S_{i} \dot{\omega}_{i}+S_{i} \dot{\omega}_{i}\right)+\frac{\rho L_{f}}{A} \dot{Q}=\rho\left(R_{i}^{2} \omega_{i}^{2}+\right. \\
& \left.R_{t}^{2} \omega_{t}^{2}+R_{s}^{2} \omega_{s}^{2}-R_{s}^{2} \omega_{i} \omega_{s}-R_{i}^{2} \omega_{s} \omega_{t}-R_{t}^{2} \omega_{s} \omega_{t}\right)+ \\
& \omega_{i} \frac{Q}{A} \rho\left(R_{i} \tan \alpha_{i}-R_{s} \tan \alpha_{s}\right)+\omega_{t} \frac{Q}{A} \rho\left(R_{t} \tan \alpha_{t}-\right. \\
& \left.R_{i} \tan \alpha_{i}\right)+\omega_{s} \frac{Q}{A} \rho\left(R_{s} \tan \alpha_{s}-R_{t} \tan \alpha_{t}\right)-p_{L}(2)
\end{aligned}
$$

Where the $\mathrm{pL}$ term represents the losses in the familiar form of shock losses from non-ideal flow conditions and fluid friction losses. These are defined as shock velocity coefficients $\left(\mathrm{Csh}_{, \mathrm{i}, \mathrm{s}, \mathrm{s}}\right)$ and a fluid friction factor (f).

$$
\begin{aligned}
& p_{L}=\frac{\rho}{2} \operatorname{sgn}(Q)\left(C_{s h, i} V_{s h, i}^{2}+C_{s h, t} V_{s h, t}^{2}+\right. \\
& \left.C_{s h, S} V_{s h, S}^{2}\right)+\frac{\rho f}{2} \operatorname{sgn}(Q)\left(V_{i}^{* 2}+V_{t}^{* 2}+V_{s}^{* 2}\right)(3)
\end{aligned}
$$

These equations fully characterize the dynamic behaviour up to sufficiently large frequencies $(\sim 50 \mathrm{~Hz})$ to model fast transient phenomena occurring during throttle steps and rapid speed ratio changes.

Due to the 'free body' formulation approach taken, the model relies upon knowing some key internal geometry parameters of the torque converter; most notably the radii and blade angles that are not normally quoted/released by torque converter manufac- 
tures. These parameters have to be calibrated before the dynamic model can be used and this is done in two stages using the Optimisation toolbox available for Dymola.

The first stage of the optimization process is to tune the model parameters so that the dynamic torque converter model accurately predicts the steady state performance. This is achieved by running the torque converter under steady state conditions and comparing the quoted steady state performance curves with the simulation results. After the optimisation of the parameters to match the steady state response, additional experimental data captured under transient driving conditions is required to calibrate the dynamic response of the torque converter model. This approach does allow the user to tune these design parameters to obtain good agreement with experimental data.

\subsection{Wet clutches}

Wet clutches are key components in both automatic and dual-clutch transmissions and a new model for predicting the torque response of a wet clutch pack has been developed. The torque across a wet clutch is a direct function of automatic transmission fluid (ATF) film thickness, pressure distribution and asperity pressure at the interface. The model calculates the total torque across the wet clutch as the sum of the hydrodynamic torque and asperity torque.

The hydrodynamic torque is created early in the clutch engagement phase through fluid shear with the hydraulic pressure supporting the normal load and preventing physical contact of the clutch plates. As the film thickness decreases to a similar magnitude to the surface roughness of the friction plates, the asperities of the friction material make contact, supporting the normal load on the clutch and reducing the fluid hydrodynamic torque to zero. The asperity torque then determines the total torque transfer. It is these phenomena that heavily influence the torque characteristics during a clutch engagement.

The hydrodynamic torque is based on the ATF film thickness $(\mathrm{h})$ calculated using an approximate Reynolds equation for a rough and permeable surface which has been shown to be very similar to the full modified Reynolds equation [4]. The contribution of the hydrodynamic pressure $(\xi)$, material permeability $(\delta)$, surface roughness $(\mathrm{g})$ and the real contact area $\left(\mathrm{A}_{\text {red }}\right)$ is given by:

$$
\frac{d \widehat{h}}{d t}=\frac{\phi(\widehat{h}) \xi(\widehat{h}) \delta(\widehat{h})}{g(\widehat{h}) A_{\text {red }}} \gamma \hat{h}^{3}
$$

The normalized oil film thickness $\hat{h}=h / h_{0}$ is used directly in the hydrodynamic torque calculation:

$$
T_{h}=\mu N_{f}\left(\phi_{f}+\phi_{f s}\right) \int_{0}^{2 \pi} \int_{r_{i}}^{r_{o}} \frac{r^{2} \omega_{r e l}}{h} r d r d \theta
$$

where h0 is the steady state oil film thickness, and the pressure and shear stress flow factors $\left(\phi_{\mathrm{f}}, \phi_{\mathrm{fs}}\right)$ from Patir and Cheng [5] account for flow between rough surfaces. The kinematic viscosity of the fluid $(\mu)$ is calculated using the ASTM D341 standard [6] as:

$$
\log \log (\mu+0.7)=A-B \log (T)
$$

where A and B are two coefficients calculated from two known viscosity-temperature operating points of the ATF.

The asperity torque is calculated from the friction coefficient $\left(\mu_{\mathrm{f}}\right)$, number of friction surfaces $\left(\mathrm{N}_{\mathrm{f}}\right)$, clutch radii $\left(\mathrm{r}_{\mathrm{i}}, \mathrm{r}_{\mathrm{o}}\right)$, and the applied pressure $\left(\mathrm{P}_{\mathrm{a}}\right)$.

$$
T_{a}=\mu_{f} N_{f} \int_{0}^{2 \pi} \int_{r_{i}}^{r_{o}} r^{2} P_{a} d r d \theta
$$

The applied pressure on the asperities on a rough surface is considered to be proportional to the area in contact and the Young's modulus of the friction material.

Due to the dependency on the ATF film thickness on clutch torque, under multiple engagements the time taken for the oil film to be replenished after an engagement would affect the torque profile for the next engagement.

As no description for this film replenishment phase seems to be available in published literature, an exponential rise time has been introduced to include the effects of multiple engagements on the oil film thickness with a parameter riseTime to describe the time taken for the film thickness to return to its pre-engagement full film thickness $\left(\mathrm{h}_{0}\right)$ :

$$
\left(\left(\frac{1-h_{0}}{\text { riseTime }}\right)\left(\exp \left(-\frac{\text { time }- \text { Htime }}{\text { riseTime }}\right)\right)\right)
$$

This models ability to account for the hydrodynamic torque contribution enables the significant thermal effects to be accounted for within the torque response in wet clutches; a common cause for negative feedback on dual clutch transmissions particularly in low temperatures at initial launch due to the high oil viscosity. This also provides a more detailed description of the real system to enable calibration of control strategies during clutch slip control and engagement.

The availability of parameter data for the clutches of interest such as the lining thickness and permeability as well as the availability of a thermal model 
that can account for the thermal performance of the system are the two significant limiting factors for the prediction of wet clutches.

\subsection{Aggregated shafts}

In the PTDynamics library, an aggregated shaft method has been developed to model the cardan shafts and joints within a driveline. The kinematic relationship of the shaft and its associated joints is described using a single aggregated joint between the two ends. Figure 3 shows an example of a shaft with a joint such as a constant velocity joint at each end of the shaft. Using this approach the shaft itself can be considered to have a fixed or variable length.

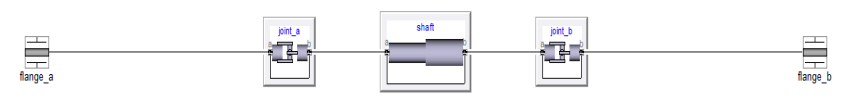

Figure 3: Diagram of an aggregated shaft with a joint at each end

This approach is consistent with the aggregated joint approach in the Modelica MultiBody library [7] where the removal of the constraint equations eliminates the nonlinear equations generated and the motion equations are solved analytically to enhance the simulation performance. Figure 4 shows how this is implemented in the PTDynamics library with the degrees of freedom for both joints being modelled in the special joint shown at the bottom of the diagram.

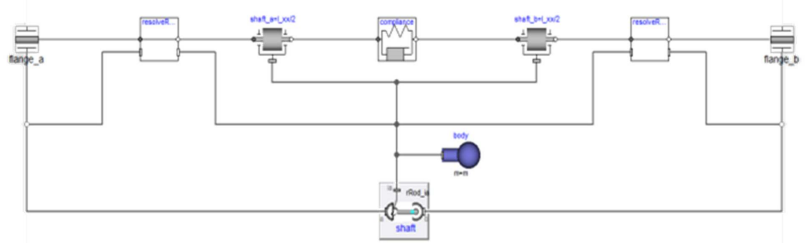

Figure 4: Internal diagram of an aggregated shaft model

One problem that can be introduced by these aggregated joints is that the MultiBody frames in the related connectors can appear to be rotated at 180 degrees relative to one another. This would make any resulting rotation that is tracked in the flange connector appear to be in the wrong direction at this point in the model (see [1] for further details on the basic Rotation3D methodology). To handle this we use special blocks that resolve the rotation direction in the flange connector to make sure that it is consistent with the orientation of the bearingFrame wherever such a rotation is possible in a component model. The resolve rotation blocks are used at both ends of the aggregated shaft model.

The topology of the shaft model can remain constant for both plunging and fixed length shafts with a simple replacement of the shaft joint at the bottom of the diagram shown in Figure 4.

The torsional compliance of the shafts in the driveline play a key role in the longitudinal response of the vehicle, with the driveshafts and propshafts often containing the largest proportion of the total compliance within the system. A compliance model is therefore included within the central shaft component and within both joints as shown in Figure 3. This compliance model can be configured to be Rigid, Linear, Linear with Backlash, Nonlinear and Nonlinear with plastic deformation to cover the different use cases and model fidelities required for driveline testing.

To aid bringing simulation earlier into the design cycle and extend the usability of the library, a number of shaft options have the ability to estimate the mechanical properties (stiffness, mass and inertia) by entering simple geometry and material properties. This can ease the burden of knowing many parameters not available early in the design stage and where simple torsion theory using geometry can yield reasonably accurate results.

\section{Vehicle Systems}

The components described have been used to model two different powertrain configurations. Built using the templates provided in the PTDynamics library, they maintain the same high level vehicle architecture but they represent very different physical systems. The template approach is based on the VehicleInterfaces library [2]. Within the PTDynamics library this architecture structure has been extended to provide templates for common transmission and driveline arrangements.

Two different powertrain architectures are considered: first, a mid-engined rear wheel drive transaxle vehicle with a dual clutch transmission; second, a front-engined rear wheel drive vehicle with an automatic transmission and torque converter.

These examples both represent a car with a mass of $1500 \mathrm{~kg}$ using a chassis model with pitch, bounce and roll degrees of freedom as well as the longitudinal motion. A mean-value engine model developed using the Engines Library [1] is used in both cases: for the four-wheel drive vehicle we use a V6 engine and for the rear-engined vehicle an inline 4 cylinder engine is used. The engine and transmission assemblies are mounted in the vehicle body using an elastomeric mount with a linear force-displacement characteristic. 


\subsection{The Transmission}

The transmissions are built using templates from the PTDynamics library as shown in Figure 5. These templates split the gearbox into 3 main sub-systems, the engagement device, the gearset and the gear selection mechanism. An engagement device in the form of a clutch assembly or torque converter sits between the engine and the gearset. The gearset includes the gears, shafts, bearings and synchronisers or clutches used to engage different gears. The gear selection mechanism defines the actuation system that translates the driver movement of the hand lever or control system gear demand into actuation of a clutch or synchroniser. This system architecture suits many applications commonly seen in automotive transmissions.

The dual clutch transmission comprises two concentric wet clutches with a three shaft type gearset as shown in Figure 6. Simple synchroniser models for each gear are included to enable the gearbox to be used to run tests in different gears but the detailed shift dynamics are not currently included and will be introduced in a future development of the PTDynamics library.

The automatic transmission is a 6 speed gearbox consisting of a front Epicyclic and a rear Ravigneaux gearset with 2 brakes and 3 clutches to control the overall gear ratio (see Figure 7). The gearset is coupled to the engine via a torque converter. The speed and torque dependent losses are lumped for convenience and based on the current gear signal. Where the data is available the losses can be distributed to the appropriate bearings and gear mesh models.

\subsection{The Driveline}

A range of templates for commonly occurring driveline configurations are provided in the PTDynamics library. The example in Figure 8 illustrates one of the four wheel drive templates that is available. In this case the driveline includes a central differential that is mounted to the transmission case. The front and rear differentials are independently, elastically mounted within the vehicle body. All of the components are replaceable so that the user can select the appropriate model for their application.

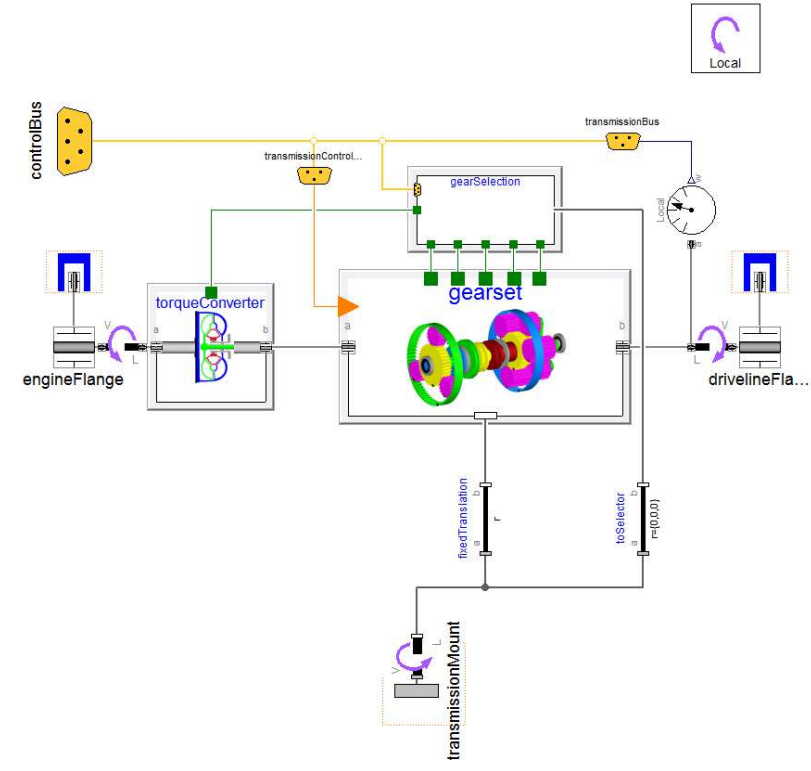

Figure 5: Automatic transmission used in the vehicle model

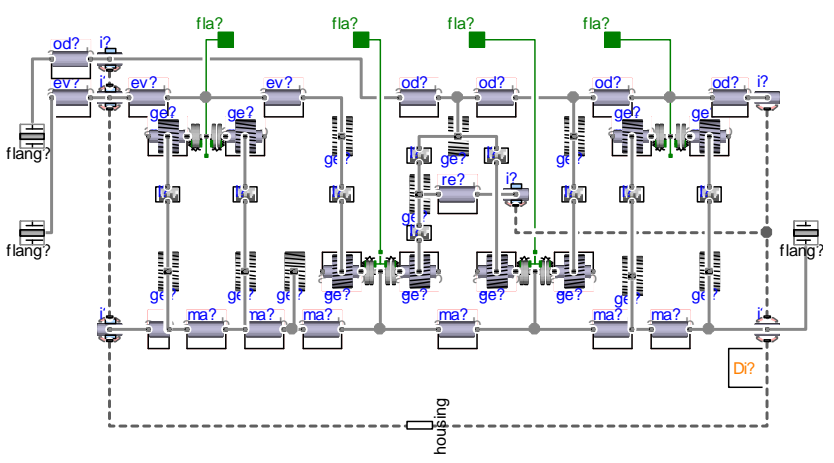

Figure 7: Dual clutch transmission 3 shaft gearset

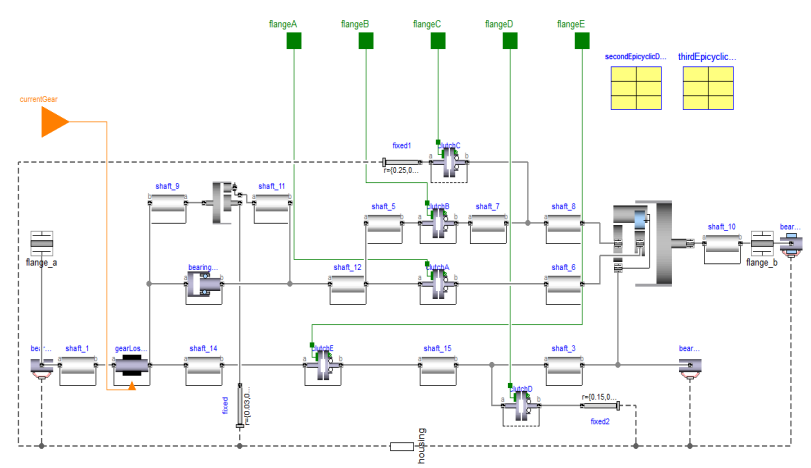

Figure 6: Gearset model for the automatic transmission model 


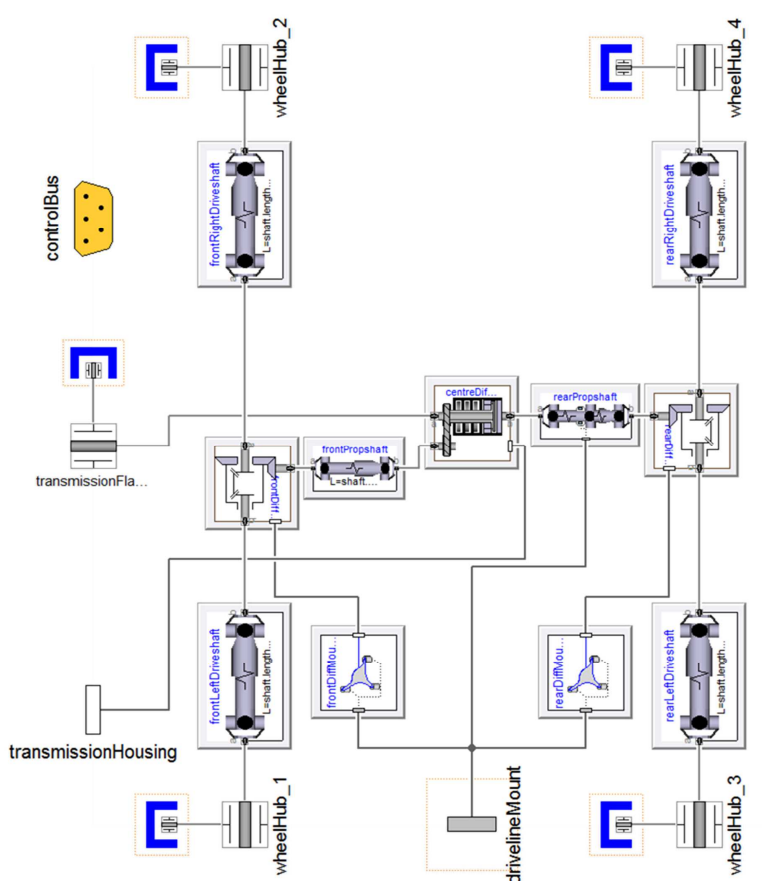

Figure 8: Four wheel drive driveline template with centre differential

\section{Results}

\subsection{Test definition}

The two powertrain examples were used to model a vehicle launch from standstill in $1^{\text {st }}$ gear. In these tests the engine starts at idle speed and we are interested in the vehicle longitudinal response which is what the driver will experience. We will focus on the behaviour and influence of the engagement devices (i.e. torque converter and wet clutch) on the longitudinal acceleration.

\subsection{Vehicle with dual clutch transmission}

The vehicle model used for these experiments is a mid-engined car with a 7 speed dual-clutch transmission and integrated rear differential. The model includes all effects that influence the initial launch of the vehicle such as the power-unit mounting system, tyre slip, suspension (including the fore-aft compliance) and the torsional compliance of all the shafts.

This example will look at the effect of oil temperature on the initial pull-away of the vehicle. With the oil in the wet clutch at the normal operating temperature the pull-away of this type of vehicle will be calibrated to deliver the acceleration profile that best matches the brand image of the manufacturer. This could result in a very smooth pull-away or be calibrated to give a more aggressive start with a higher jerk at the start of the launch. However the start is calibrated, the aim for the manufacturer is for this to be consistent at all operating temperatures of the clutch. At low temperatures though, this becomes more difficult to achieve due to the change in viscosity of the oil. This change is usually obvious to the driver because the launch will not be as smooth and a lot of effort with the calibration is required to minimise the effect.

The launch test is a gentle acceleration with the driver requesting a small amount of the available engine torque resulting in the vehicle accelerating to just $20 \mathrm{kmh}$ in 5 seconds. Figure 9 shows the results of this pull away for the cold and warm gearbox tests. In the case of the warm pull away the accelera-
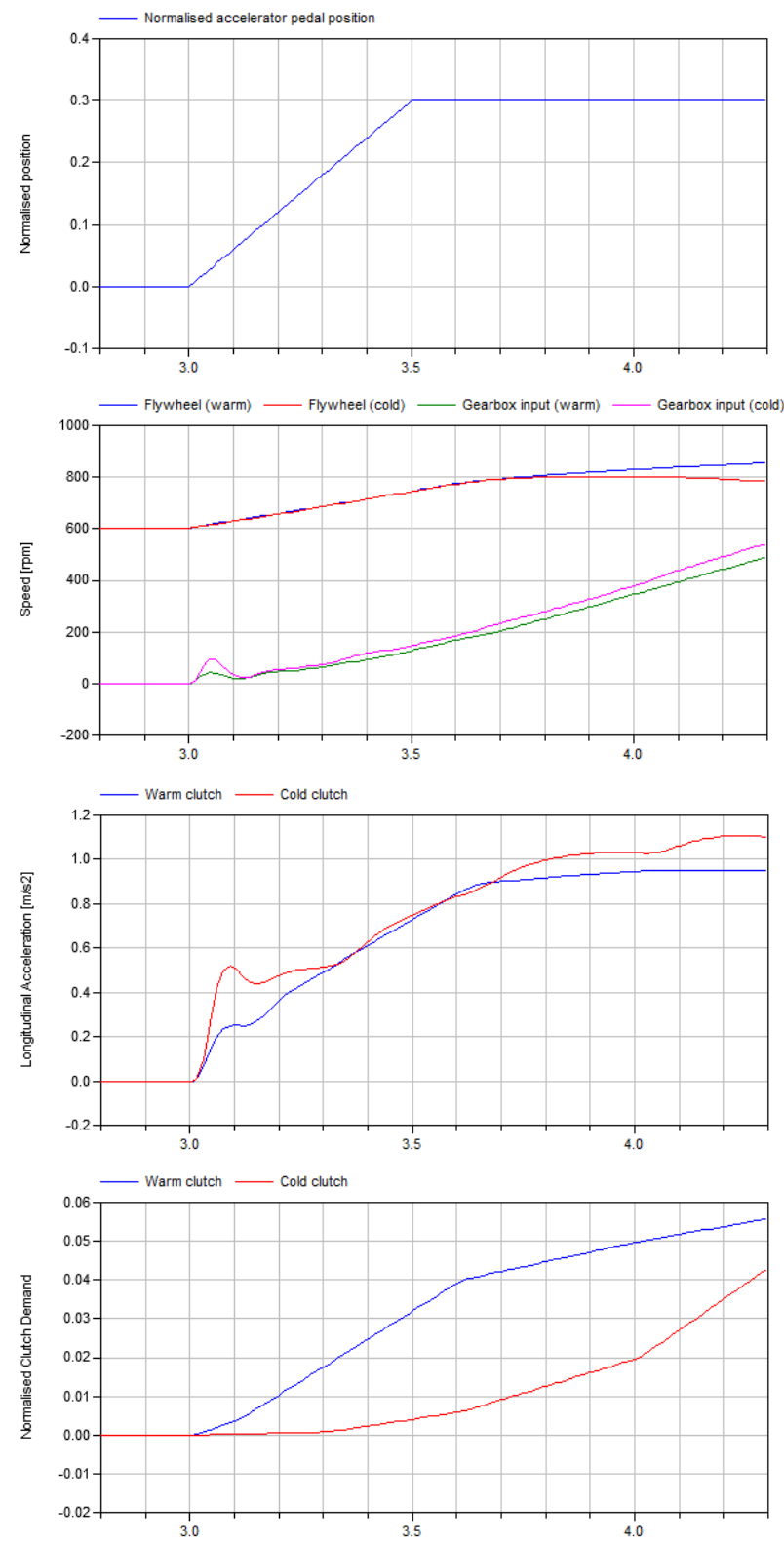

Figure 9: Comparison of pullaway with warm and cold oil in the wet clutch. Top is the driver accelerator demand; 2nd plot is the engine and gearbox input speeds; 3rd is the longitudinal acceleration; and bottom is the clutch demand 
tion builds very smoothly.

With the cold gearbox though a smooth pull-away is not achieved even though the clutch demand is significantly reduced due to the low oil temperature. The bottom plot in Figure 9 shows the change in the clutch demand between the warm and cold oil temperatures. Despite the large reduction in the clutch demand during the first $0.2 \mathrm{~s}$, when the oil temperature is low we still get a relatively large acceleration as soon as the clutch pressure begins to rise. This is due to a large amount of torque that gets generated as soon as the fluid layer begins to be compressed resulting in a torque spike and corresponding longitudinal acceleration.

How the driver judges the driveability performance of a vehicle is often related to 3 objective variables: delay time; peak acceleration and jerk [8]. Looking at these 3 objective measures using Figures 9 and 10 we can interpret the vehicle response and compare the cold and warm performance. There is no change in delay time but there is a big increase in the jerk (See Figure 10) and a related change in the acceleration profile (see Figure 9). For the cold pullaway event, the jerk is $2.5 \mathrm{x}$ higher than with a warm clutch. This will all effect the drivers perception of how smooth the car is.

To cope with the low oil temperature the clutch engagement profile has to be reshaped as well as reducing the actual applied pressure during the early phases of the engagement.

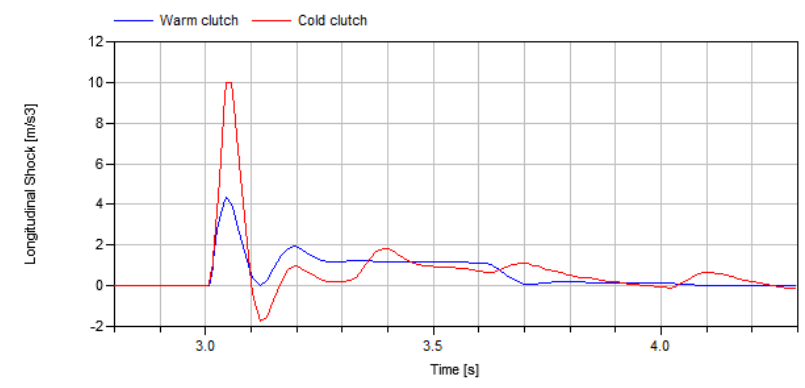

Figure 10: Longitudinal jerk during pullaway

\subsection{Vehicle with automatic transmission}

The vehicle model used for these experiments is a front-engined, rear-wheel drive vehicle. It is fitted with a 6 speed automatic transmission with a torque converter and lock-up clutch. The model includes all effects that influence the initial launch of the vehicle such as engine and differential mounting systems, tyre slip, suspension (including the fore-aft compliance) and the torsional compliance of all the shafts.

The torque converter model can be easily changed between a steady state model and the calibrated dynamic model. This analysis focuses on the detailed differences in the vehicle response due to the use of a steady state and dynamic torque converter model.

The experiment is a launch from rest with the driver releasing the brake pedal and then applying the accelerator pedal. The rate of pedal actuation is the same in both tests and the engine is running at idle speed with first gear engaged in the transmission at the start of the test. Therefore the only difference between the two tests is the torque converter model.

Figure 11 shows the normalised driver pedal posi-
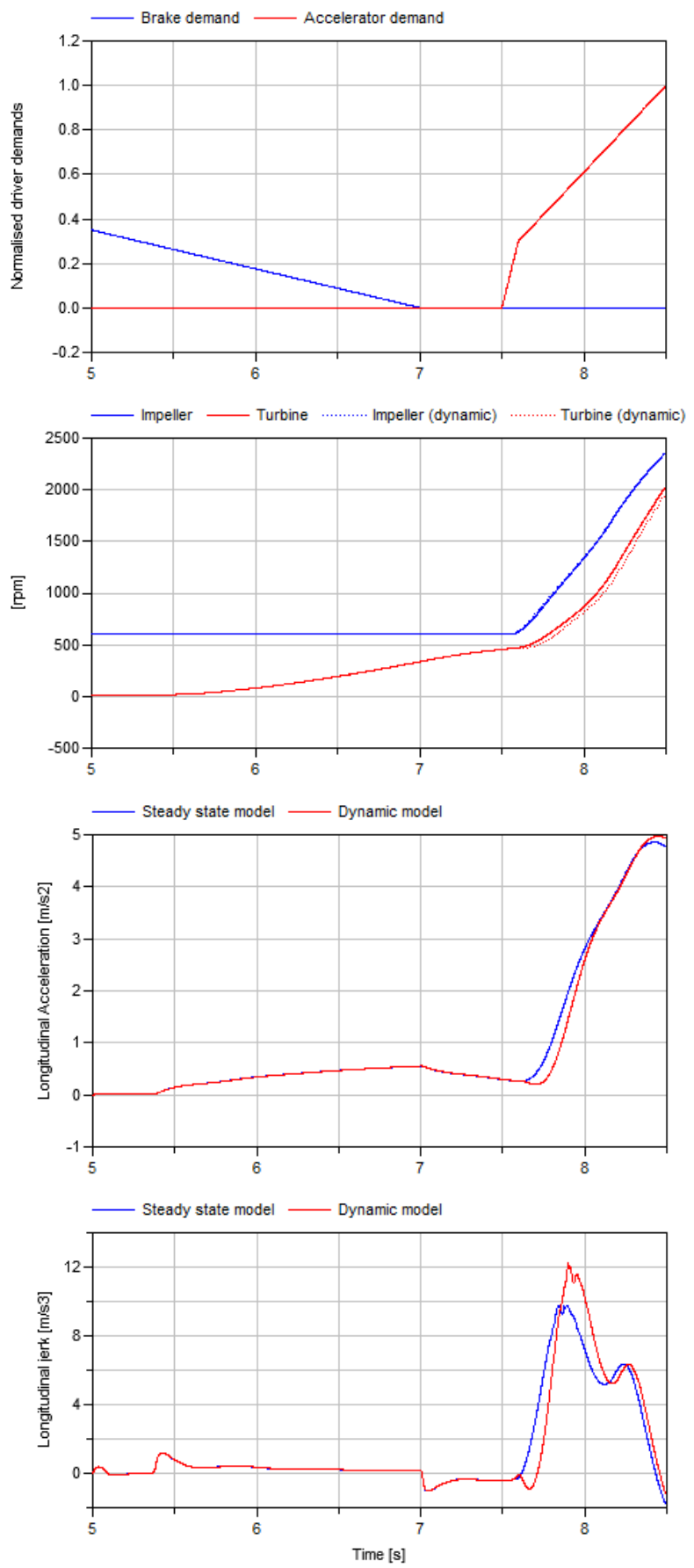

Figure 11: Pullaway comparing the steady state and dynamic torque converter models. Top: driver demands; $2^{\text {nd }}$ plot is the impeller and turbine speeds with the dynamic model results in dashed lines; $3^{\text {rd }}$ is the longitudinal acceleration; Bottom is the longitudinal jerk 
tions (top graph) aligned with the impeller and turbine speeds (middle graph) and the vehicle longitudinal acceleration (bottom graph).

The longitudinal acceleration of this vehicle can be broken down into two phases. Phase 1 occurs between 5.0 and $7.0 \mathrm{~s}$ while the brakes are slowly released and phase 2 begins as the driver steps across from the brake pedal to the accelerator pedal.

During phase 1 the acceleration profile is dominated by the release characteristics of the brake system. This is because while the vehicle is held stationary the torque converter is applying torque to the gearbox input. As soon as the friction torque in the brakes reduces below a certain level the vehicle will will start to creep forward. This model includes a very simple brake system and so the brake pedal release profile is modified to limit the acceleration during phase 1.

Phase 2 of the launch is where we see the differences between the steady state and dynamic torque converter models. At this stage in the test the driver is quickly applying the accelerator pedal to demand $100 \%$ torque from the engine and it is during the time 7.5 to 8.0 s that we see the effect of the torque converter model on the results.

With the dynamic torque converter model we see an increased delay between the driver demand and the vehicle acceleration combined with an increase in the jerk once the dynamic model starts to accelerate. Both of these metrics are known to influence the drivers perception of driveability [8].

Accurate prediction of these driveability metrics together with other measurements such as fuel usage, emissions and thermal effects enable the launch strategy within the engine control software to be adjusted and calibrated to deliver the desired balance between vehicle performance feel, fuel economy and emissions.

\section{Conclusions}

An overview of the developments made within the Powertrain Dynamics Library is presented and focused on the prediction of initial launch for two types of vehicle. In the first case, the effect of oil temperature on the initial launch of a dual wet-clutch transmission equipped vehicle is presented followed by a look at how a dynamic torque converter model can improve the accuracy of the initial launch prediction of an automatic transmission equipped vehicle.

Two key areas for transmission modelling have been addressed through the introduction of more detailed wet clutch models and a dynamic torque converter model. These enable more dynamic driving events such as launch and gear shifting to be modelled and accurately predicted using Modelica based models.

\section{References}

[1] Dempsey M., and Picarelli A. Investigating the MultiBody Dynamics of the Complete Powertrain System. Como, Italy: Proceedings $7^{\text {th }}$ Modelica Conference, 2009.

[2] Dempsey M., Gäfvert M., Harman P., Kral C., Otter M., and Treffinger P., Coordinated automotive libraries for vehicle system modelling, Vienna, Austria, Proceedings of the 5th International Modelica Conference, 2006.

[3] Hrovat D., and Tobler W.E., Bond-graph modelling and computer simulation of automotive torque converters. Journal of the Franklin Institute 319,93-114, 1985

[4] Yang Y., Lam R., and Fujii T., Prediction of Torque Response During the Engagement of Wet Friction Clutch. SAE Technical Paper, 981097, 1998.

[5] Patir N., and Cheng H., Application of Average Flow Model to Lubrication Between Rough Sliding Surfaces. ASME Journal of Lubrication Technology, 101, 220, 1979

[6] American Society for Testing and Materials (ASTM) International. D341 -09 Standard Practise for Viscosity-Temperature Charts for Liquid Petroleum Products, Accessed 08/05/2012 http://www.astm.org/Standards/D341.htm

[7] Otter M., Elmqvist H., and Mattsson S.E.: The New Modelica MultiBody Library, Linkoping, Sweden, Proceedings of the Modelica 2003 Conference, 2003

[8] E. Cacciatori, Advanced Control Concepts for a Parallel Hybrid Powertrain with Innitely Variable Transmission," Ph.D. dissertation, Cranfield University, Cranfield, 2007. 